Project 1024773

\title{
Biogeochemical Cycling and Environmental Stability of Pu Relevant to Long-Term Stewardship of DOE Sites
}

\author{
Francis, Arokiasamy J. \\ Brookhaven National Laboratory \\ Santschi, Peter $\mathrm{H}$. \\ Texas A\&M University at Galveston \\ Honeyman, Bruce D. \\ Colorado School of Mines
}

RESULTS TO DATE: Biogeochemical Cycling and Environmental Stability of Pu Relevant to Long-Term Stewardship of DOE Sites (May 2005)

B. D. Honeyman1, A. J. Francis2, C. J. Dodge2, J.B. Gillow2 and P. H. Santschi3 1Environmental Science and Engineering Division, Laboratory for Applied and Environmental Radiochemistry, Colorado School of Mines, Golden, CO 80401; 2Environmental Sciences Department, Brookhaven National Laboratory, Upton NY 11973; 3Department of Oceanography, Texas A\&M University at Galveston, Galveston, TX 77551

Because the RIMS system does not support special characters, figures, equations or tables, the full report is available from the NABIR program managers or the PI (honeyman@mines.edu). The text below is an extended summary of the project results to date.

I. Overview. The overall objective of this proposed research is to understand the biogeochemical cycling of Pu in environments of interest to long-term DOE stewardship issues. Central to Pu cycling (transport initiation to immobilization) is the role of microorganisms. The hypothesis underlying this proposal is that microbial activity is the causative agent in initiating the mobilization of Pu in near-surface environments: through the transformation of Pu associated with solid phases, production of extracellular polymeric substances (EPS) carrier phases, and the creation of microenvironments. Also, microbial processes are central to the immobilization of Pu species, through the metabolism of organically complexed Pu species and $\mathrm{Pu}$ associated with extracellular carrier phases and the creation of environments favorable for $\mathrm{Pu}$ transport retardation.

This project is collaboration among the Colorado School of Mines (Honeyman, Diaz and Tinnacher), Brookhaven National Laboratory (Francis, Gillow and Dodge) and Texas A\&M University (Santschi, Hung, Schwehr, Roberts). This report outlines the results of work performed by this collaborative group during the first reporting phase of this project (approximately October 1, 2004 - May 31, 2005).

The sub-projects focused on this year include: A. Biotransformation of Pu-contaminated Soil B. Characterization of Rocky Flats soil C. 'Static' column experiments D. Radiolabeling of natural organic matter with tritium. E. Preliminary plutonium transport experiments. F. Production, isolation and characterization of EPS (exopolymeric substances). G. Production, isolation and characterization of Puorganic iron-containing colloids from RFETS soils that have been shown to be one of the vectors for dispersal of Pu. H. Immobilization potential of bacterial EPS for Pu bound to different colloidal phases.

II. Summaries of Individual Sub-Projects. A. Biotransformation of Pu in Contaminated Soil. Summary: The addition of glucose to RFETS soil and incubation under anaerobic conditions resulted in fermentative 
microbial activity that decreased the $\mathrm{pH}$ to $\sim 5.5$ and resulted in significant iron dissolution. A 242Pu tracer was used to track the fate of $\mathrm{Pu}$ and it was detected in the $<0.45$ micrometer fraction concomitant with microbial activity; the Pu is currently undergoing characterization by micro- and ultrafiltration. The addition of lactate to the soil resulted in microbial activity (the $\mathrm{pH}$ remained at $\sim 7$ ) and little iron reduction. The 242Pu was also detected in the $<0.45$ micrometer fraction due to microbial activity; dissolution peaked at $\sim 3$ days and then it slowly became 'dissolved' (i.e., filter-passing) with a constant amount detected ( $\sim 3-4$ $\mathrm{pCi} / \mathrm{ml}$ in the less than $<0.45$ micrometer fraction) from 24 to 54 days. Experiments with a 242Pu tracer reproduce previous studies that showed 239Pu in the solution phase due to microbial activity. Additional studies are underway to examine the fate of the indigenous $239,240 \mathrm{Pu}$ (by alpha spectroscopy) in soil incubations in order to fully evaluate the suitability of the tracer Pu as a proxy for the indigenous $\mathrm{Pu}$. In addition, the solid-phase association of 242Pu and $239,240 \mathrm{Pu}$, as well as the iron oxide content, will be determined in unamended and amended soils before and after biotransformation. Finally, we are focusing on investigating the correlation between Pu in association with iron oxides, their dissolution by microbial action, and the ultimate fate of $\mathrm{Pu}$ (readsorbed and/or in association with a microbially-produced organic colloid).

\section{B. Rocky Flats Soil Characterization.}

During the summer of 2004, approximately $150 \mathrm{lb}$. of Pu-contaminated soil from the 903 'lip area' of the Rocky Flats Environmental Technology Site were collected for use during this project. Substantial effort was made during this first portion of the project to size-classify the soil ( $<2 \mathrm{~mm}$ fraction), and to determine project-relevant soil properties (e.g., soil pH, Pu and organic carbon content)

C. 'Static' Column Experiments. Static columns are in the process of being employed using Rocky Flats soil and stimulation of indigenous soil microorganisms by the addition of glucose as an electron donor. The goal of these experiments is to evaluate the potential of glucose fermentative conditions for initiating Pu transport.

C1. Tracer Test. The tracer tests show that the conservative tracer $3 \mathrm{H}$ is quantitatively removed after approximately $5 \mathrm{~mL}$ of flushing solution has been added.

C2. Incubation Experiments. Static column experiments are currently in their initial stages. Incubation conditions will follow those of the batch experiments described in Section A.

D. Radiolabeling of Natural Organic Matter with Tritium (CSM). Understanding the role of natural organic matter (NOM), such as extracellular polymeric substances (EPS), in the biogeochemical cycling of plutonium requires the ability to accurately monitor the concentration of such organic ligands in time and space at relatively low concentrations (i.e., $\mathrm{mg} / \mathrm{L} \mathrm{C}$ or less). Radiolabeled NOM can provide a means of tracing NOM at low levels, for relatively low cost, using standard radioanalytical equipment. Requirements of such a radiolabel include chemical stability over time, a high degree of consistency and replication in the labeling technique and a high label specific activity. In establishing this radiolabeling technique for NOM we took aim at addressing some of the limitations of current methods.

Summary. In the new procedure, fulvic acid is radiolabeled with tritium by its reduction with tritiated sodium borohydride ( $\mathrm{NaBH} 4)$ at alkaline $\mathrm{pH}$ and slightly elevated temperatures (Leenheer et al., 1987). The reactant selectively reduces the carbonyl groups of aromatic and aliphatic ketones as well as quinones. This results in the formation of tritium-labeled secondary alcohols. Only the alcohols formed from aliphatic ketones are assumed to be stable in aerobic environments over time.

The labeling efficiency in terms of reduced reactive fulvic acid groups is in the range of 100 percent with equal weights of fulvic acid and $\mathrm{NaBH} 4$ in the reaction solution. Using equal weights of fulvic acid and $\mathrm{NaBH} 4$ in the reaction solution will yield specific activities on the order of 50 to 100 microCi / mg fulvic acid, which is expected to be sufficient for the quantification of organic matter at low concentrations. 
One mathematical and two quasi-chemical models were developed to describe the efficiency of the labeling reaction, and to allow the tailoring of the label to the specific activity required for any desired application in the future. In summary, all of these models show good fits of the efficiency data.

E. Preliminary Plutonium Transport Experiments. Summary. A preliminary column transport experiment was performed to investigate the potential effects of extracellular polymeric substances on plutonium transport behavior. Results to date suggest that plutonium forms solution complexes with EPS that are chemically stable under transport conditions. Furthermore, recovery data ssuggest that substantial amounts of plutonium and the organic ligand were irreversibly sorbed to the mineral phase.

F. Production, Isolation and characterization of EPS (exopolymeric substances). EPS were isolated by the TAMUG group from three bacterial species: a) two aerobic soil bacteria: Shewanella putrefaciens CN32, and Pseudomonas fluorescens Biovar II; and b) one anaerobic bacterium, Clostridium sp. BC1.

Summary. The neutral monosaccharides in EPS from Pseudomonas fluorescens Biovar II consist of rhamnose, fucose, ribose, arabinose, xylose, mannose, galactose and glucose. The acidic groups in this EPS are mainly composed of carboxylic acid and minor polyanionic groups, e.g., sulphate and phosphate. Up to $70 \%$ of total carbohydrates are uronic acids, and total carbohydrates made up 26-31\% of organic carbon. Besides the neutral and acidic sugars in the EPS, EPS also contained $2 \%$ of proteins in terms of carbon, which makes the EPS amphiphatic (amphiphilic).

$1 \mathrm{~kg}$ of Pu-contaminated soils from Rocky Flats will be used by the TAMUG group to extract sufficient quantities of $\mathrm{Pu}$ into distilled water to allow the isolation of the Pu-binding macromolecular assembly by gel electrophoretic separation of the Pu fraction from isoelectric focusing (IEF) and 2-dimensional polyacrylamide gel electrophoresis (2-D PAGE).

Microbially produced EPS act as a sorptive sponge or colloid trap (Hoffman and Decho, 1999) through a combination of steric, hydrophobic and hydrophilic interactions. Confirmation of such a colloid trap model come from the AFM and TEM results (Santschi et al., 1998, Wilkinson et al., 1999), which show abundant fibrils covered by smaller spherical colloids. Colloid trapping by mineral particles appears to be responsible also for the observed enhancement of the $\mathrm{Kd}$ value for $\mathrm{Pu}(\mathrm{IV})$ onto mineral particles such as silica, as compared to the linear sum of the individual Kd values (e.g., calculated from silica and EPS as end-members). Experiments on Pu(IV) (and Th(IV) as a screening tool) sorption to colloidal silica of different surface area and pore space, in the presence or absence of model acid polysaccharides (e.g., alginate, xanthan, etc.), as well as EPS harvested from soil bacteria will be carried out.

Research on colloidal characterization involving the hydrophobic or hydrophilic interactions of EPS and APS by the TAMUG group has progressed in the areas of experimental determination of octanol-water partitioning coefficient values (Kow) via shake-flask and slow-stir methods, and in size exclusion chromatography (SEC). More specifically, Kow values were determined for a series of different molecular weight anionic dextrans, whereby it was found that Kow values increase with increasing molecular weight. Replicate experiments show that Kow values of APS compounds increase in the following order: alginic acid > lambda carrageenan > xanthan > lipopolysaccharide (from Shewanella) > gellan > kappa carrageenan.

The TAMUG group also started calibration experiments for obtaining Pu(IV) binding EPS ligands using gel electrophoretic separation of the Pu fraction from isoelectric focusing (IEF) and 2dimensional polyacrylamide gel electrophoresis (2-D PAGE; Quigley et al., 2002), combined with potential functional group characterization using 14C- labeling of the carboxyl group, as well as sulphate and phosphate analysis of the IEF or molecular weight fraction (Alvarado-Quiroz et al., 2005) that contains Pu(IV).

References cited in the text. Alvarado-Quiroz, N.A., Hung, C.-C., and Santschi, P.H. 2005. Binding of Thorium(IV) to carboxylic acid, phosphate and sulfate functional groups from marine exopolymeric substances (EPS), Mar. Chem., in revision. 
Carter, Martin, R. (ed.) for Canadian Society of Soil Science: Soil Sampling and Methods of Analysis, Lewis Publishers, Boca Raton - Ann Harbor - London - Tokyo, 1993.

Hung, C.-C., Santschi, P.H., and Gillow, J.B. 2005. Isolation and characterization of extracellular polysaccharides produced by Pseudomonas fluorescens Biovar II. Carbohydrate Polymers, in press.

Leenheer, J.A., Wilson, M.A., Malcolm, R.L. 1987. Presence and potential significance of aromatic-ketone groups in aquatic humic substances. Org. Geochem., 11, 4, 273-280.

Quigley, M. S., Santschi, P. H., Guo, L. and Honeyman, B. D. 2001. Sorption irreversibility and coagulation behavior of 234Th with surface-active marine organic matter. Mar. Chem. 76: 27-45.

Quigley, M.S., Santschi, P.H., Hung, C.-C., Guo, L., and Honeyman, B.D. 2002. Importance of polysaccharides for 234Th complexation to marine organic matter. Limnology and Oceanography, 47, 367-377.

Ron, E.Z., and Rosenberg, E. 2001. Natural roles of biosurfactants. Env. Microbiol., 3, 229-236.

Santschi, P.H., Balnois, E., Wilkinson, K., Zhang, J., Buffle, J., and Guo, L. 1998. Fibrillar polysaccharides in marine macromolecular organic matter, as imaged by Atomic Force Microscopy and Transmission Electron Microscopy, Limnology and Oceanography, 43(5), 896-908.

Santschi, P.H., K.A. Roberts, and L. Guo (2002). Organic nature of colloidal actinides transported in surface water environments. Environ. Sci. Technol. 36:3711-3719.

Tamura, T., "Physical and Chemical Characteristics of Plutonium in Existing Contaminated Soils and Sediments," Proceedings of the Symposium on Transuranium Nuclides in the Environment, IAEA Pub ST1/PUB/410, Vienna, 1976.

Twigg, R.S. 1945. Oxidation-reduction aspects of resazurin. Nature, 3935, 401-402.

Wilkinson, K.J., E. Balnois, G.G. Leppard and J. Buffle. 1999. Characteristic features of the major component of freshwater colloidal organic matter revealed by transmission electron and atomic force microscopy. Colloids and Surfaces A. Physiochemical and Engineering Aspects 155:287-310.

DELIVERABLES: Kantar, C. and B.D. Honeyman. Binding of Pu to alginic and citric acids. Radiochim. Acta, in review.

Roberts, K.A., Santschi, P.H., Leppard, G.G., and West, M. (2004). Characterization of organic-rich colloids from surface and ground waters at the actinide-contaminated Rocky Flats Environmental Technology Site (RFETS), Colorado, USA. Colloids and Surfaces A: Physicochem. Eng. Aspects, 244, 105-111.

Roberts, K.A., and Santschi, P.H. (2004). Inverse dependency of particle residence times in ponds to the concentration of phosphate, the limiting nutrient. J. Environ. Radioactivity, 76(3), 311-318.

Hung, C.-C., Santschi, P.H., and Gillow, J.B. (2005). Isolation and characterization of extracellular polysaccharides produced by Pseudomonas fluorescens Biovar II. Carbohydrate Polymers, in press.

COLLABORATIONS: Bruce Honeyman, Colorado School of Mines Peter Santschi, Texas A\&M University 
